07

\title{
Определение толщин и особенностей легирования многослойных 4H-SiC-структур методом частотного анализа инфракрасных спектров отражения
}

\author{
(C) А.В. Афранасьев, В.И. Зубков, В.А. Ильин, В.В. Лучинин, М.В. Павлова, М.Ф. Панов , В.В. Трушлякова, \\ Д.Д. Фирсов
}

Санкт-Петербургский государственный электротехнический университет „ЛЭТИ“, Санкт-Петербург, Россия

IE-mail: 19_panov_59@mail.ru

Поступило в Редакцию 3 сентября 2021 г.

В окончательной редакции 22 сентября 2021 г.

Принято к публикации 7 октября 2021 г.

\begin{abstract}
Разработана методика частотного анализа инфракрасного спектра отражения для определения толщин и порядка расположения слоев в эпитаксиальной структуре карбида кремния. Выполнены расчеты для эпитаксиальной структуры $4 \mathrm{H}$-SiC. Показана высокая чувствительность метода к оптическим границам, возникшим в результате последовательного увеличения уровня легирования в процессе роста слоя.
\end{abstract}

Ключевые слова: карбид кремния, эпитаксиальный слой, ИК-отражение, спектр.

DOI: 10.21883/PJTF.2022.02.51919.19012

Уникальная совокупность электрофизических свойств карбида кремния политипной модификации $4 H(4 H-\mathrm{SiC})$ позволяет создавать на его основе приборы силовой электроники, которые существенно превосходят кремниевые аналоги по таким важнейшим параметрам, как величина сопротивления активной области, потери при переключении, плотность коммутируемой мощности, рабочие температура и частота. Поэтому развитие карбидокремниевой электронной компонентной базы обусловливает применение новых эффективных и оперативных методов анализа приборных эпитаксиальных структур (ЭС), в том числе контроля толщин слоев, существенно влияющих на характеристики приборов $[1,2]$.

При падении электромагнитных волн на плоскопараллельный образец часть излучения отражается от границы раздела воздух-верхний слой, часть проходит в ЭС, где происходит серия отражений и преломлений от межслойных границ. Те волны, которые преломляются и двигаются в обратном направлении на границе верхний слой-воздух, интерферируют с волнами, отраженными от верхней границы структуры. Зависимость амплитуды интерференции от длины волны, регистрируемая фотоприемником, имеет периодический характер и является спектральной интерференцией. Разность хода интерферирующих волн определяется расстоянием от поверхности структуры до границы, на которой волна испытала отражение. Поэтому в спектре отражения присутствуют компоненты, соответствующие толщине верхнего слоя $d_{n}$, суммарной толщине верхнего и следующего слоя $d_{n}+d_{n-1}$ и т. д. Экспериментальные спектры отражения, измеренные на двух ЭС $4 H-\mathrm{SiC}$, представлены на рис. 1 , а соответствующие им технологические характеристики слоев и результаты измерений, полученные в настоящей работе, приведены в таблице. Каждой спектральной компоненте в приближении постоянного показателя преломления $(n \approx 2.64[3])$ можно сопоставить толщину слоя, вычисляемую как $d=\left(2 \omega^{\prime} n\right)^{-1}$ [4], где $\omega^{\prime}-$ период интерференционных спектральных колебаний. Визуальное определение величин периодов колебаний в спектре (особенно низкочастотных „биений“), которые являются суперпозицией синусоид, не представляется возможным, так как оно может давать одинаковые результаты для различных сочетаний исходных периодов. Следовательно, необходим частотный фурье-анализ спектра отражения.

Для корректного определения толщин эпитаксиальных слоев используется спектральная область отражения структуры, где материал - карбид кремния - не имеет линий поглощения и его показатель преломления обладает малой нормальной дисперсией. Поэтому для характеризации многослойных ЭС $\mathrm{SiC}$ : 1) из исполь-

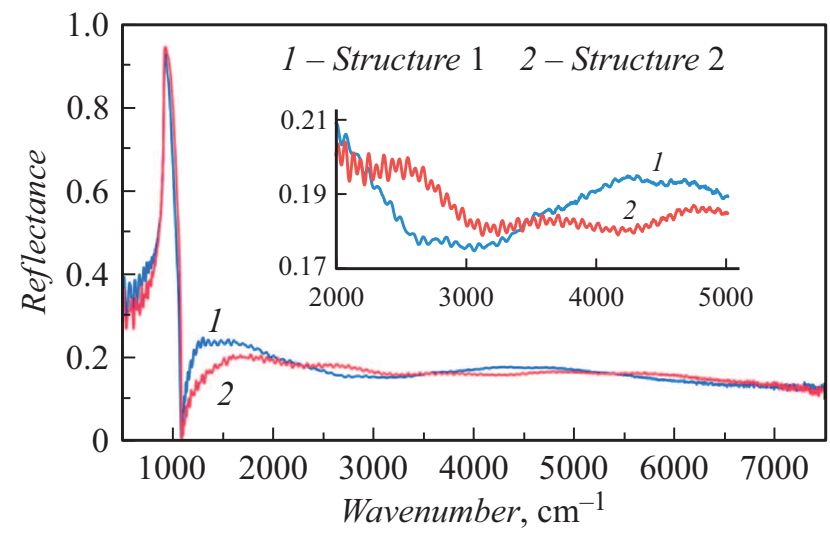

Рис. 1. Экспериментальные спектры отражения. На вставке участок в увеличенном виде. 
Паспортные данные ЭС 1 и 2 и результаты фурье-анализа спектров отражения

\begin{tabular}{|c|c|c|c|c|c|c|c|}
\hline \multirow{2}{*}{$\begin{array}{l}\text { Номер } \\
\text { струк- } \\
\text { туры }\end{array}$} & & \multirow[t]{2}{*}{ Параметр } & \multicolumn{5}{|c|}{$\begin{array}{c}\text { Параметры эпитаксиальных слоев } \\
\text { (нумерация от подложки) }\end{array}$} \\
\hline & & & 1 & 2 & & 3 & \\
\hline \multirow[t]{2}{*}{1} & $\begin{array}{l}\text { Техничес- } \\
\text { кий } \\
\text { паспорт }\end{array}$ & $\begin{array}{l}\text { Тип проводимости } \\
\text { Концентрация примеси, } \mathrm{cm}^{-3} \\
\text { Толщина, } \mu \mathrm{m}\end{array}$ & $\begin{array}{c}n^{+} \\
5 \cdot 10^{18} \\
10\end{array}$ & $\begin{array}{c}p \\
1 \cdot 10^{16} \\
16\end{array}$ & \multicolumn{3}{|c|}{$5 \cdot 10^{18} \underset{5}{\rightarrow} 1 \cdot 10^{20}$} \\
\hline & \multicolumn{2}{|c|}{ Толщина по спектру (рис. $2, a), \mu \mathrm{m}$} & 9.25 & 16.4 & 2.05 & 2.05 & 1.03 \\
\hline \multirow{3}{*}{2} & $\begin{array}{l}\text { Техничес- } \\
\text { кий } \\
\text { паспорт }\end{array}$ & $\begin{array}{l}\text { Тип проводимости } \\
\text { Концентрация примеси, } \mathrm{cm}^{-3} \\
\text { Толщина, } \mu \mathrm{m}\end{array}$ & $\begin{array}{c}n^{+} \\
5 \cdot 10^{18} \\
10\end{array}$ & $\begin{array}{c}p \\
1 \cdot 10^{16} \\
16\end{array}$ & \multicolumn{3}{|c|}{$5 \cdot 10^{18} \underset{2.5}{\rightarrow} 1 \cdot 10^{20}$} \\
\hline & \multicolumn{2}{|c|}{ Толщина по спектру (рис. $2, b), \mu \mathrm{m}$} & 12.7 & 15.5 & 1.11 & 1.11 & 0.553 \\
\hline & \multicolumn{2}{|c|}{ Толщина по спектру (рис. $2, c), \mu \mathrm{m}$} & 12.8 & 15.6 & 1.11 & 1.11 & 0.556 \\
\hline
\end{tabular}

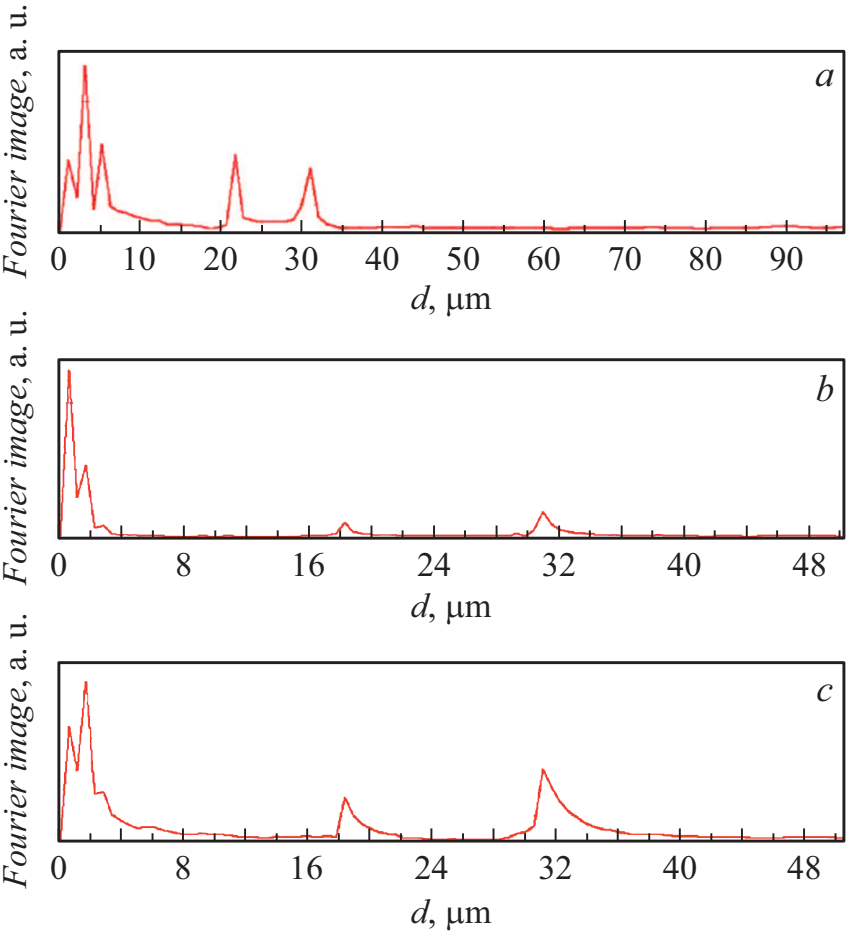

Рис. 2. Результаты фурье-анализа спектров отражения. $a$-структура $1 ; b-$ структура 2 , диапазон $2370-5783 \mathrm{~cm}^{-1}$; $c$ - структура 2 , диапазон $1843-5240 \mathrm{~cm}^{-1}$.

зуемого для частотного анализа спектра исключается область однофононного (вблизи $1000 \mathrm{~cm}^{-1}$ ) и плазмонного (менее $1000 \mathrm{~cm}^{-1}$ ) резонансов $\left.[5,6] ; 2\right)$ при работе с экспериментальной спектральной кривой удаляется линия тренда, возникающая вследствие существующей малой дисперсии показателя преломления.

Результат обнаружения интересующей нас гармоники в спектре фурье-преобразования зависит от того, целое ли число ее периодов укладывается в анализируемую область. Если их число не целое, то в спектре фурье-преобразования появляются пики на частотах, которые не соответствуют реальным накладывающимся гармоникам, но находятся рядом с реальными, при одновременном уменьшении амплитуды реальных пиков. Поэтому для минимизации появлений в спектре фурьепреобразования „побочных“ пиков, а также выявления и повышения амплитуды „истинных“ пиков производится корректировка анализируемого диапазона, направленная на использование при фурье-преобразовании целого числа периодов исследуемой части гармоники.

На рис. 2 приведены результаты фурье-анализа исследованных структур, отградуированные в толщинах слоев. Следует помнить, что первый пик указывает на толщину верхнего слоя, второй пик - на суммарную толщину верхнего слоя и слоя, лежащего под ним, и далее в той же последовательности. Минимальная определяемая толщина в соответствии с диапазонами спектра составляет около $0.5 \mu \mathrm{m}$.

Использованный в работе алгоритм для анализа спектра отражения карбидокремниевых ЭС является весьма чувствительным. Он, например, позволил зафиксировать наличие оптических границ в структуре высоковольтного меза-эпитаксиального $4 \mathrm{H}$-SiC $p-i-n$-диода, в котором на $p$-слое с относительно низкой концентрацией нескомпенсированных акцепторов $\left(N_{A^{-}} N_{D}=5 \cdot 10^{15} \mathrm{~cm}^{-3}\right)$ создан высоколегированный $p^{+}$-эмиттер [7]. Выход на высокий, практически предельный по алюминию в $\mathrm{SiC}$ уровень легирования осуществляется в процессе эпитаксии поэтапно благодаря разработанной ранее технологии [8]. На рис. 3 приведено полученное методом растровой электронной микроскопии (РЭМ) изображение типичной для таких приборных структур области эмиттера, где контраст изображения указывает на наличие подслоев с различной концентрацией акцепторной примеси. На рис. 2 можно видеть пики в фурье-образах спектра, соответствующие толщинам подслоев, а в таблице приведены 


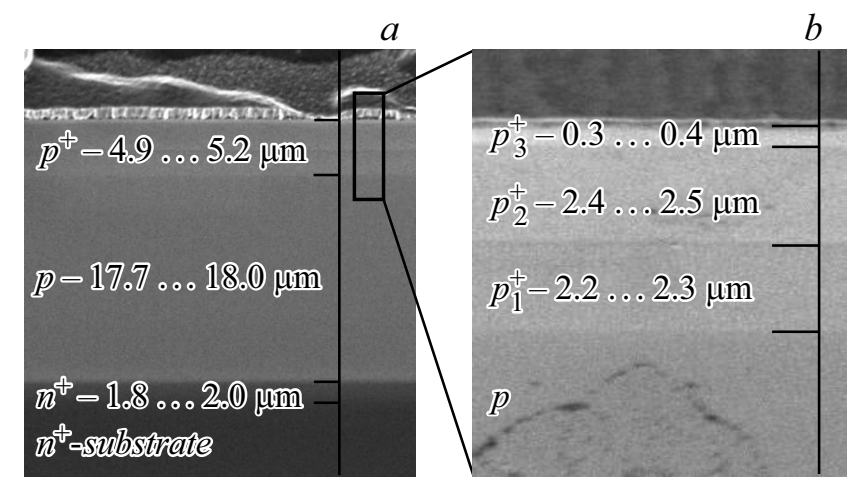

Рис. 3. РЭМ-изображение приборной карбидокремниевой ЭС в режиме контраста легирования. $a-$ послойный состав ЭС, $b-$ состав $p^{+}$-эмиттера.

численные значения толщин подслоев, определенные бесконтактным способом в настоящей работе.

Таким образом, в работе продемонстрирован бесконтактный способ определения толщин в приборных карбидокремниевых структурах политипа $4 H$, который чувствителен к оптическим границам как между специально созданными функциональными областями ЭС, так и между слоями, возникающими в результате управления процессом осаждения. С применением частотного анализа спектров отражения в области ближнего и среднего ИК-диапазонов одновременно определены толщины пяти эпитаксиальных слоев, что позволяет применять разработанную методику для неразрушающего анализа многослойных ЭС $4 \mathrm{H}-\mathrm{SiC}$.

\section{Финансирование работы}

Работа выполнена при финансовой поддержке Минобрнауки РФ (проект № 03.G25.31.0243).

\section{Конфликт интересов}

Авторы заявляют, что у них нет конфликта интересов.

\section{Список литературы}

[1] S. Oishi, Y. Hijikata, H. Yaguchi, S. Yoshida, Jpn. Soc. Appl. Phys., 45 (46), L1226 (2006). DOI: 10.1143/JJAP.45.L1226

[2] Z.-Y. Li, J.-W. Sun, Y.-M. Zhang, Y.-M. Zhang, X.-Y. Tang, Chin. Phys. Lett., 27 (6), 068103 (2010). DOI: $10.1088 / 0256-307 \mathrm{X} / 27 / 6 / 068103$

[3] Handbook of optical constants of solids, ed. by E.D. Palik (Academic, San Diego, 1998).

[4] В.В. Батавин, Ю.А. Концевой, Ю.В. Федорович, Измерение параметров полупроводниковых материалов $и$ структур (Радио и связь, М., 1985).

[5] K. Narita, Y. Hijikata, H. Yaguchi, S. Yoshida, S. Nakashima, Jpn. J. Appl. Phys. A, 43 (8), 5151 (2004). DOI: $10.1143 / J J A P .43 .5151$
[6] М.Ф. Панов, Ф.Е. Рыбка, В.П. Растегаев, в сб. V Межсдисциплинарный научный форум „Новые материалы и перспективные технологии“ (М., 2019), т. 1, с. 377.

[7] А.В. Афанасьев, В.А. Голубков, В.А. Ильин, В.В. Лучинин, А.А. Рябко, К.А. Сергушичев, В.В. Трушлякова, С.А. Решанов, Изв. ЛЭТИ, № 6, 72 (2020).

[8] А.В. Афанасьев, В.А. Ильин, В.В. Лучинин, С.А. Решанов, Изв. вузов. Электроника, 25 (6), 483 (2020). DOI: $10.24151 / 1561-5405-2020-25-6-483-496$ 